\title{
The Losses of Ascorbic Acid during the Large-scale Cooking of Green Vegetables by Different Methods
}

\author{
By MARGARET A. ALLEN AND S. G. BURGESS \\ Chemical Branch, London County Council, County Hall, Westminster Bridge, \\ London, S.E. I
}

(Received 26 April 1949)

This work was undertaken to find out whether in large-scale cooking more ascorbic acid is retained when green vegetables are added in successive portions to boiling water than when they are added all at once in the traditional manner. The Accessory Food Factors Committee of the Medical Research Council (194I) referred to the destruction of ascorbic acid by oxidative enzymes present in raw vegetables. This action was said to be accelerated by increase in temperature until the enzymes are inactivated, which occurs within a few degrees of the boiling-point of water. In consequence, it was recommended that 'vegetables should be put in gradually or in small amounts at a time, so that the water does not go off the boil'. Gould, Tressler \& King (1936) found that $25 \%$ of the ascorbic acid in raw cabbage was destroyed during the time $(2 \mathrm{~min}$. in their experiments) before the cooking water returned to the boil and that no further destruction took place during subsequent cooking. Lampitt, Baker \& Parkinson (1943) found that with cabbage the average destruction was significantly less when the vegetable was added to the water slowly than when it was added at once. With kale, brussels sprouts and several other vegetables they found no significant difference. In largescale cooking, conditions may differ considerably from those obtaining in domestic practice or laboratory experiments, for example the rate of heat input relative to thermal capacity is much less, causing a longer cooking time and hence increased oxidation. Branion, Roberts, Cameron \& McCready (1948) reported a greater loss of ascorbic acid in large-scale than in small-scale cooking of cabbage, but Wood, Collings, Stodola, Burgoin \& Fenton (1946) found no significant difference in destruction when different quantities of cabbage were cooked in the same relative amount of water.

\section{METHODS}

\section{Cooking procedures}

In this investigation a standardized procedure was adopted, so that as far as practicable, considering the difficulties of large-scale cooking experiments, the only variable was the ascorbic-acid content, and the sampling was so arranged that each test of the two methods should be complete in itself, with sufficient analyses to justify statistical treatment. The work was conducted in two London County Council school kitchens: in one about $50 \mathrm{~kg}$. ( $\mathrm{c} \mathrm{cwt}$.) of vegetable were cooked in a gas-heated 1821 . (40 gal.) boiler, and in the other about $13 \mathrm{~kg}$. (30 lb.) in an electrically heated 1361 . ( 30 gal.) appliance. The two cooking methods, namely, the addition of the vegetable all at 
once or in four successive portions, were compared in the same boiler, on the same day, and with, as far as practicable, similar material and the same rate of heat input. The whole of the vegetable to be cooked on one day was coned, quartered and divided into two batches and was prepared by removing the outer leaves and cores, shredding by hand, washing and draining. It was weighed before and after washing, and the amount of entrained water, which was of the order of $0.53-0.631 . / \mathrm{kg} .(6-7 \mathrm{gal} . / \mathrm{cwt}$.), added to that placed in the boiler gave a final water:vegetable ratio of about $2: 1$. Sodium chloride was added in sufficient amount to produce an initial concentration of $1 \%$ and the lid was kept on the boiler throughout the cooking period. 'The vegetable was added either all at once or in four equal portions when the water was boiling; with the latter method it was brought back to boiling-point before each addition. When the vegetable was judged to be tender it was removed and pressed in colanders, the expressed water being returned to the boiler for the final measurement of the cooking water. The temperature of the water was observed after each addition and the total cooking time recorded.

As practical difficulties prevented the weighing of the cooked vegetable, the average change in weight was calculated from total-solids determinations, this procedure having been proved valid in a separate series of experiments.

\section{Sampling}

Each batch of vegetable, obtained as stated above, was shredded and divided into four portions, and from each ten subsamples were taken at random. These were bulked together to give four samples of about $100 \mathrm{~g}$. vegetable. Ten samples of cooked vegetable were taken and also a volume of the liquor remaining after the cooking operation. All samples for ascorbic-acid estimation were placed in tared bottles containing sufficient $10 \%$ metaphosphoric acid to give a final concentration of approx. $5 \%$. Separate samples of raw and cooked vegetable were taken for moisture determination, and of cooking liquor for total-solids estimation.

\section{Estimation of ascorbic acid}

The whole contents of the tared bottles were macerated in a Waring Blendor; after centrifuging, a portion was titrated in an atmosphere of nitrogen. 'The method employed was essentially that of Harris \& Olliver (1942).

\section{RESULTS}

The results are summarized in Tables $I$ and 2.

Table I shows the mean ascorbic-acid content of the raw and cooked vegetable, with the corresponding standard errors, and that of the cooking liquor together with the details of the cooking conditions. Table 2 shows the percentage retention, extraction and destruction of ascorbic acid by the two cooking methods (see p. 95) together with their differences and the $P$ values for retention differences. Mean results are also given for the cabbage experiment. The experiments with cabbage were triplicated, so that the variation of mean values could be investigated, because in the restaurants under 
Vol. 4

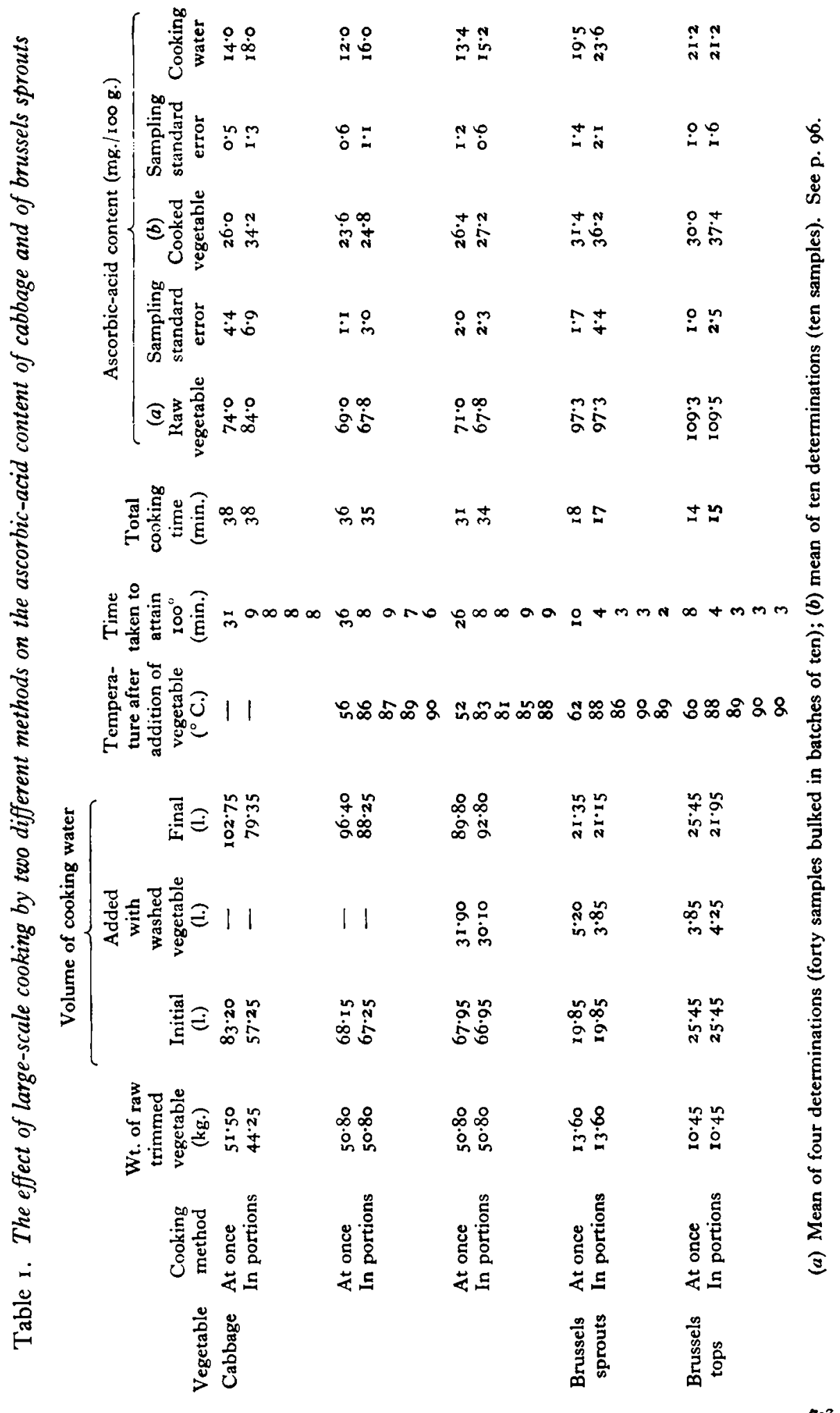


Table 2. The percentage of ascorbic acid retained in the vegetable, extracted by the cooking water and destroyed by cooking, with the probable significance of the results

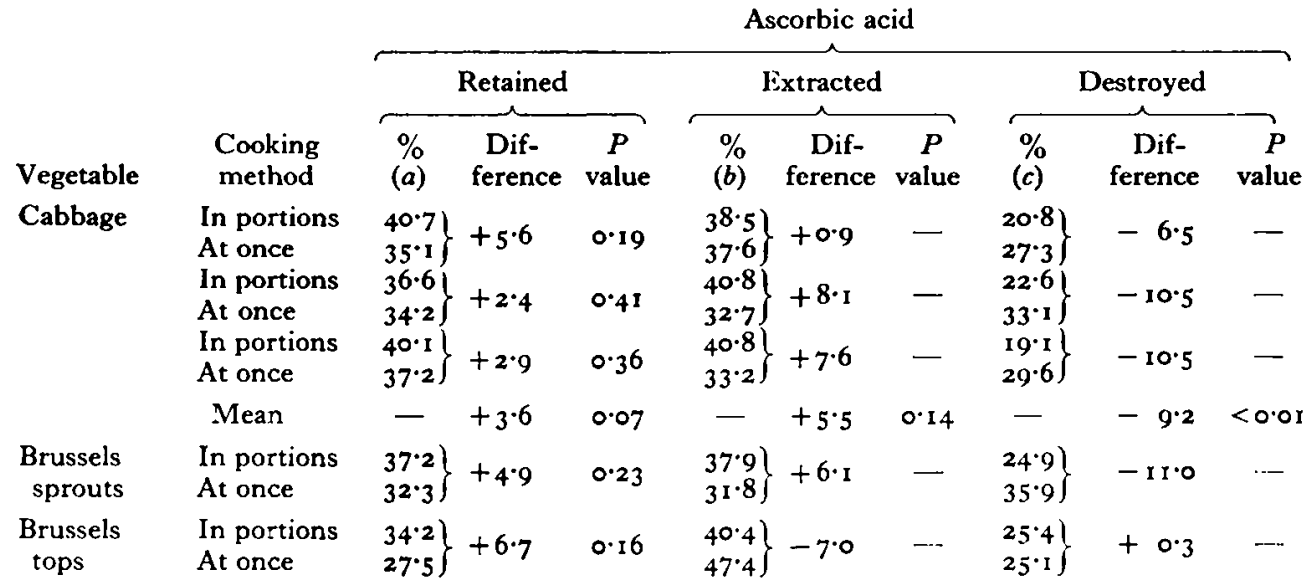

(a) Calculated from the mean results on forty samples of raw, and ten samples of cooked, vegetable; (b) calculated from the weight of cooking water and its ascorbic-acid content; $(c)$ roo- $(\%$ retained + $\%$ extracted).

consideration cabbage is served far more frequently than other green vegetables. It will be seen that the temperature fell from $100^{\circ}$ to $52-62^{\circ}$ when the vegetable was added all at once, whereas it did not fall below $8 \mathrm{I}^{\circ}$, and was usually $85^{-}-90^{\circ}$, when it was added in four separate portions and returned to the boil after each addition. A survey of the figures given in Table $\mathrm{I}$ of the ascorbic-acid contents of the raw and cooked vegetables shows an apparent slight advantage in retention from adding the vegetable in portions. However, considering the sampling difficulties of this type of work, as shown by the standard errors, it is necessary to examine the results statistically (see Table 2) before significance can be established. The average of all the results obtained shows that $36 \%$ of the ascorbic acid was retained, $38 \%$ extracted by the water and $26 \%$ destroyed.

\section{DISCUSSION}

A survey of the results reported in the literature of cooking experiments carried out under comparable conditions reveals considerable differences in the distribution of ascorbic acid after cooking. In small-scale experiments, when a water:cabbage ratio similar to ours was adopted, the retention of ascorbic acid ranged fron 35 to $52 \%$ (mean $47 \%$ ) and destruction from 12 to $24 \%$ (mean $17 \%$ ) (Allen \& Mapson, 1944; Van Duyne, Chase \& Simpson, 1944; Lampitt, et al. 1945). Branion et al. (1948), in a direct comparison, obtained a retention of $38 \%$ on a small scale and $28 \%$ with large quantities. Wood et al. (1946), cooking ro and $50 \mathrm{lb}$. batches of cabbage in the same proportion of water as we used, reported retentions of $50-57 \%$ and a destruction of

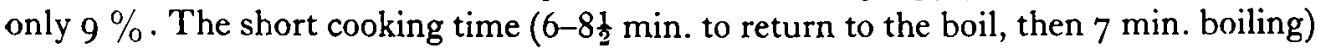
used by these workers may account for the high retention and low destruction.

The ascorbic acid retained in our experiments is thus near the lower end of the range reported by previous workers and the amount destroyed tends to be high. With brussels sprouts the amount of ascorbic acid lost by extraction and destruction was of 
the same order as with cabbage. Lampitt et al. (1943) obtained retentions of $64 \%$ and no destruction of ascorbic acid in the cooking of brussels sprouts by either method; Olliver ( 1941 ), however, reported $3^{6-53} \%$ retained and $3^{-13} \%$ destroyed in smallscale experiments. It is probable that in our experiments the shredding of this vegetable and the different conditions of large-scale cooking account for the destruction being greater than that obtained by previous workers, but these variations are considered to be of secondary importance in our investigation to the comparative retention values with the different methods of cooking. In the experiments with brussels tops, in spite of every effort to maintain constant heat input for the two parts of the work, more water was evaporated when the vegetable was cooked by adding it in portions. This did not affect appreciably the relative cooked weights of the vegetable, but the extraction of ascorbic acid was less than when the vegetable was added at once and the destruction loss was about the same in both parts of the experiment. In view of the number of samples taken, this cannot be due to error, and the most probable explanation is considered to be more vigorous boiling of the water, causing more decomposition of the ascorbic acid extracted.

In previous work by Lampitt et al. (1943) with cabbage (on a small scale) the mean retention when the vegetable was added gradually was found to be $4 \%$ higher, the leaching losses $6 \%$ higher and the destruction $10 \%$ lower, than when it was added all at once. The corresponding figures shown in Table 2 as the mean differences of the cabbage experiments obtained under different conditions indicate good agreement with these results. Lampitt et al. (1943) thus showed that the decreased destruction resulting from gradual addition was to a considerable extent counterbalanced by an increase in extraction, so that the difference in retention was small. The mean values for our experiments also support this conclusion. When the variation of the samples was considered, the difference in destruction was shown to be significant but it was not proved $(P>0.05)$ that the retention and extraction differences for the two methods were significant, although the former was suggestive. For brussels tops and brussels sprouts the difference in retention was also not shown to be significant.

In view of the differences previously reported on a small scale, it may be hardly justifiable to consider these different types of green vegetables together, yet it is interesting to calculate the value of $P$ for retention differences in all the pairs of experiments; this was found to be 0.01 and the difference is therefore regarded as significant.

From a practical viewpoint the method of adding the vegetable in portions would only be of importance for ascorbic-acid intake if each experiment had shown a statistically significant difference in retention; for the small or doubtful advantage demonstrated the extra labour and time involved in this method would not be justified.

\section{SUMMARY}

I. The ascorbic-acid contents of cabbage, brussels sprouts and brussels tops have been determined before and after cooking by different methods on a large scale. In one method the vegetable was added all at once and in the other it was added at intervals, in four separate equal portions, the water being brought back to the boil before each addition. 
2. The results obtained for cabbage showed that the mean increase in retention when this vegetable was added in portions was $3.6 \%$, the extraction was $5.5 \%$ greater, and the destruction was $9.2 \%$ less. These results are in good agreement with previously published work on a small scale but in these experiments on a large scale, when the variation of samples was taken into account, although the difference in destruction was statistically significant, the advantage for retention was doubtful and was not proved to be significant.

3. With brussels sprouts and brussels tops the increases obtained in percentage retention were respectively $4 \cdot 9$ and $6 \cdot 7$, but these were not statistically significant.

4. In work with this type of raw material sufficient results must be obtained to be treated statistically. Arithmetical means that do not take into consideration the variation in the samples may be misleading.

5. Work on this subject is being continued.

The authors wish to express their thanks to Mr B. Benjamin, B.Sc., F.I.A., for help and advice with the statistical analysis of the results, and to Messrs J. H. Barker, B.Sc., F.R.I.C., and W. H. F. Jackman, B.Sc., A.R.I.C., for their assistance with the large number of chemical determinations involved.

Our sincere thanks are also due to Mr C. J. Regan, B.Sc., F.R.I.C., Chemist-inChief to the London County Council and Mr T. F. Macrae, O.B.E., Ph.D., D.Sc., F.R.I.C., for the assistance and valuable criticism generously given, and also to Sir Allen Daley, M.D., F.R.C.P., K.H.P., Medical Officer of Health, and Mr W. J. O. Newton, C.B.E., Chief Officer of the Restaurants and Catering Department, for providing the facilities to carry out this work.

\section{REFERENCES}

Accessory Food Factors Committee of the Medical Research Council (I 94I). Lancet, $240,838$.

Allen, R. J. I.. \& Mapson, L. W. (1944). Y. Soc. chem. Ind., Lond., 63, 78.

Branion, H. D., Roberts, J. S., Cameron, C. R. \& McCready, A. M. (1948). F. Amer. diet. Ass. 24,10 r.

Gould, S., 'Tressler, D. K. \& King, C. G. (1936). Food Res. 1, 427.

Harris, L. J. \& Olliver, M. (1942). Biochem. Y. 36, 155.

Lampitt, L. H., Baker, L. C. \& Parkinson, 'Г. L. (1943). F. Soc. chem. Ind., Lond., 62, 61.

Lampitt, L. H., Baker, I. C. \& Parkinson, T. L. (1945). Y. Sac. chem. Ind., Lond., 64, 260.

Olliver, M. (1941). Chem. E Ind. 60, 586.

Van Duyne, F. O., Chase, J. T. \& Simpson, J. I. (1944). Food Res. 9, 164.

Wood, M. A., Collings, A. R., Stodola, V., Burgoin, A. M. \& Fenton, F. ( 1946). F. Amer. diet. Ass. 22, 677. 